\title{
The range of applying the faculty assistants for strategies of effective teaching of students of home economics in Faculty of Effective teaching
}

\author{
Mohamed. H. Abd Elshafy
}

Faculty of Education, South Valley University

\begin{abstract}
It is the responsibility of the mathematics teacher to achieve educational aims that transcend the limits of information teaching, to acquire the teaching of higher thinking skills in mathematics, by planning educational attitudes that enable them to acquire knowledge, and to develop various mathematical skills such as creative proofing skills, The study group consisted of (38) students one experimental group and the following materials and tools were applied: (the training program, the achievement test to measure the cognitive aspects included in the program, the observation card to measure the skills of teaching creative proofing, The results of the study showed The effectiveness of the training program in developing the skills of teaching creative proofing among the students of the mathematics and collection development department in relation to the cognitive aspects included in the program.
\end{abstract}

Keywords: Training Program; Teaching Creative Proofing Skills

Citation Elshafy,Requirements of Electronic Management in the Management of Kindergarten Institutions. SVU-Journal of abstract 2019, Vol.1: pp20 (retrieved from the Journal of Educational Sciences; 2018, No.35; pp 317).

Copyright: Publisher South Valley University.This is an open-access article distributed under the terms of the creative commons attribution license, which permits unrestricted use, distribution and reproduction in any medium provided the original author and source are created. 